\title{
Influence of Hydrothermal Condition and Topography on Dynamic of Vegetation Coverage in Inner Mongolia
}

\author{
Wendurina $^{1}$, Yuhai Bao ${ }^{1,2, *}$, Yinshan ${ }^{1}$, \\ 1.Inner Mongolia Normal University, School of Geographical Sciences, Hohhot 010022, China \\ 2.Inner Mongolia Normal University, Key Laboratory of Remote Sensing and Geographic Information, Hohhot \\ 010022, China

\section{水热条件和地形因子对内蒙古植被覆盖变化的 影响} \\ 温都日娜 ${ }^{1}$, 包玉海 ${ }^{1,2, *}$, 银山 ${ }^{1}$ \\ 1.内蒙古师范大学 地理科学学院, 内蒙古呼和浩特 010022 \\ 2. 内蒙古师范大学 内蒙古自治区遥感与地理信息重点实验室, 内蒙古呼和浩特 010022
}

\begin{abstract}
:
Vegetation cover is a good indicator for evaluation terrestrial environment. The research on the response of hydrothermal conditions and the relationship with the topographic condition has become one of the main contents. The annual dynamics and spatial variability of vegetation in Inner Mongolia were studied based on the MODIS NDVI datasets during 2000-2014.The response of vegetation cover to hydrothermal conditions and topography was analyzed.It gets the following conclusion:The growing season vegetation cover,on the whole,trended increase in recent 15years. The correlation analysis of vegetation cover and hydrothermal conditions factor indicated that the precipitation and land surface water index were primary factors of vegetation dynamics. There is different trend of vegetation change based on the different altitude,slope and aspect.
\end{abstract}

*通讯作者：包玉海

E-mail: baoyuhai@imnu.edu.cn。
Keywords : vegetation cover ; Hydrothermal Conditions; Topographic factor; Inner Mongolia

\section{摘要:}

植被是生态环境变化的综合指示器, 研究其对 水热条件的响应以及与地形的关系成为当前 植被变化驱动力研究中的主要内容之一。基于 2000-2014年 MODIS NDVI 数据, 分析了内蒙古 地区植被覆盖变化趋势及空间差异, 并结合水 热条件和地形数据分析了植被变化趋势与水 热条件、地形的关系。结果表明: 内蒙古地区 生长季植被覆盖变化呈恢复趋势。与水热条件 因子的相关分析证实了生长季植被覆盖变化 趋势主要受降水量和地表水分含量的控制。不 同高程、坡度、坡向上的植被变化趋势存在较 大差异。

关键词: 植被覆盖, 水热条件, 地形因子, 内 蒙古地区

1. 引言

陆地生态系统是人类赖以生存与可持续发展 的生命支持系统, 植被处于陆地表面特殊位置, 是大气、水分、土壤、岩石等长期相互作用的 
产物, 更是陆地生态系统的重要环节, 植被覆 盖变化很大程度代表了生态环境变化的总体 状况, 是生态环境变化的综合“指示器”[1]。植 被的发展变化与多种因素有关, 包括地球表面 水热条件、地形等诸多自然因子, 又涉及到人 类活动的影响。

内蒙古地处我国北部边疆地区, 是我国北 部重要的生态屏障, 位于 $37^{\circ} 24^{\prime}-53^{\circ} 23^{\prime} \mathrm{N}$ $97^{\circ} 12^{\prime}-126^{\circ} 04^{\prime} \mathrm{E}$, 属于干早半干早气候向 东南沿海湿润半湿润季风气候的过渡带 ${ }^{[2]}$, 受 温度和水分条件的综合影响, 植被带主要表现 为近经向的空间分异特征, 从东到西依次为 山地针叶林和阔叶林带、森林草原带、典型草 原带、荒漠草原带和荒漠带 ${ }^{[3]}$ 。内蒙古自治区 是我国重要的农牧业生产基地, 人类活动强度 大, 且大部分植被地处干旱、半干旱农牧交错 带地区, 生态环境脆弱, 因此研究该区域植被 变化及其驱动因子对研究区生态环境建设具 有重要的理论和现实意义。

遥感技术在植被覆盖动态监测和模拟研 究中被广泛使用, 主要提供长时间序列的植被 覆盖观测和生物物理参数反演资料, 用于分析 时空变化趋势。MODIS 产品虽然生产时间短, 但因具有更高的空间分辨率和时间分辨率, 能 够快速方便地获取大区域地表信息, 成为植被 动态和地表水热条件研究的一种重要数据源 $[4,5]$ 。基于此, 选取内蒙古自治区作为研究区, 利用2000-2014年 MODIS 数据（NDVI、LSWI、 LST )、同期气象站点数据和 DEM 数据, 以线性 趋势分析、相关分析方法为基础，分析近 15 年来植被覆盖变化及其气温、降水量、地表温 度 (LST) 和地表水指数 (LSWI) 等水热条件 和地形因子响应, 分析水热条件和地形因子对 植被覆盖变化的影响, 旨在揭示各因素影响下 的植被变化过程, 为生态环境建设提供科学的 决策依据。

\section{2. 数据与方法}

\section{1. 数据来源与预处理}

遥感数据来源于美国国家航空航天局提供的 MODIS 产品, 其中包 MOD13A3和 MOD11A2。 MOD13A3 为空间分辨率 $1 \mathrm{~km}$ 的月度产品, 用于 提取 NDVI 指数和近红外和中红外波段数据。 MOD $11 \mathrm{~A} 2$ 为空间分辨率 $1 \mathrm{~km}$ 的 $8 \mathrm{~d}$ 合成产品, 用
于提取地表温度指数 (LST)。其中考虑到冬季 积雪影响, 每年4-10月数据用于研究。在 MRT、 ENVI 等遥感图像处理软件环境下, 对研究区 每景数据进行拼接、投影转换和裁剪等预处理。 其中地表水指数的计算公式如下 ${ }^{[6]}$ :

$$
\mathrm{LSWI}=\frac{\mathrm{R}_{\text {nir }}-\mathrm{R}_{\text {mir }}}{\mathrm{R}_{\mathrm{nir}}+\mathrm{R}_{\text {mir }}}
$$

式中, $R_{n i r}$ 为近红外波段, $R_{\operatorname{mir}}$ 为中红外波 段。

气象数据来源于中国气象科学数据共享 服务网, 包括内蒙古地区 48 个气象站点, 数 据内容为 2000-2014 年每年 4-10月 (生长季) 的月平均气温和月总降水量。在此基础上获得 每个气象站点的年平均气温和年总降水量数 据。

DEM 数据从地理空间数据云服务平台获得, 其空间分辨率为 $90 \mathrm{~m}$, 利用 ArcGIS 软件提取研 究区高程、地面坡度、坡向。

\section{2. 研究方法}

最大值合成方法: 采用国际上惯用的最大值合 成法 (MVC), 对 $8 \mathrm{~d}$ 合成的 LST 数据进行处理, 该处理可以减少大气的云、颗粒、阴影、视角 以及太阳高度角的影响 ${ }^{[7]}$ 。在 ENVI 中, 利用 波段计算器模块, 得到2000-2014年4-10月每 月 LST 数据。同时将每月的 NDVI、LSWI 和 LST 数据按均值合成, 得到了 2000-2014年间的年 均植被 NDVI 数据和地表水热组和数据。

线性趋势分析方法: 本文采用线性趋势 分析方法研究该区2000-2014年植被覆盖与水 热条件变化趋势, 它可以模拟每个栅格的变化 趋势, 反映不同时期的植被变化趋势的空间特 征。趋势显著性采用 $\mathrm{F}$ 检验。计算公式如下 ${ }^{[8]}$ :

$$
a=\frac{\sum_{i=1}^{n}\left(\mathrm{x}_{i}-\mathrm{x}\right)\left(\mathrm{y}_{i}-\mathrm{y}\right)}{\sum_{i=1}^{n}\left(\mathrm{x}_{i}-\mathrm{x}\right)^{2}}
$$

式中, $a$ 为变化趋势, 即斜率, 正值表示 增加趋势, 负值表示减少趋势; $\mathrm{x}_{i}$ 为第 $i$ 年 的区域平均 NDVI 值, $\mathrm{X}$ 为多年平均 NDVI 值, $\mathrm{y}$ 为研究阶段的年数。

相关分析方法: 采用相关分析法研究 NDVI 


\section{Risk Analysis and Crisis Response in Big Data Era (RAC-16)}

与水热因子的关系, 统计计算相关系数 ${ }^{[9]}$ 。

\section{3. 结果与分析}

\section{1. 植被覆盖时空变化特征}

2000-2014年内蒙古植被 NDVI 生长季变化过 程如图1所示, 近15年来内蒙古地区植被覆盖 变化总体上呈增加趋势, 增加速度为 $0.0015 / \mathrm{a}$ 。 并且增加趋势较为显著 $(R 2=0.435)$ 。这表明 研究区植被覆盖度趋于好转态势。上述 NDVI 时间序列是研究区内所有像元的平均结果, 所 体现的是研究区整体变化趋势, 并没有反映出 植被空间变化趋势的差异。因此将线性趋势分 析方法拓展到像元尺度上, 获得生长季逐像元 植被 NDVI 变化趋势图, 反映2000-2014年间研

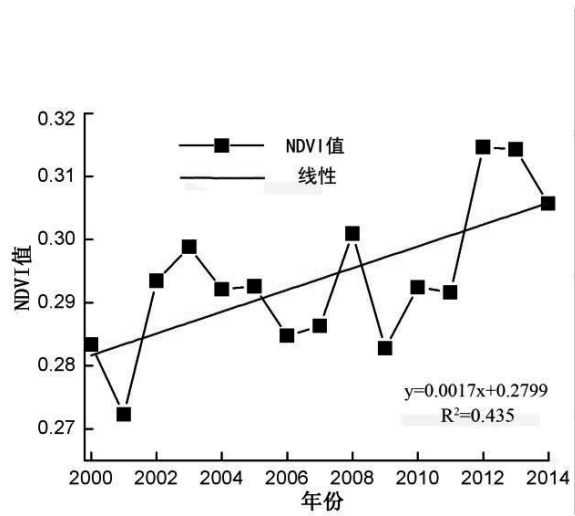

图 1 2000-2014 年内蒙古生长季 NDVI 年际变化

\section{2. 驱动因子分析}

植被是同时受各种环境因素影响的结果，气象、 水热、地形地貌等是决定植被状况的重要因素。 气候, 地表水热条件等因素有于它们的易变性, 往往决定了一个地区的植被长势。地形因素有 于它们的稳定性, 因此它们对植被的影响也是 稳定的，往往影响的只是植被的空间分布，年 际不会出现很大的变化。本章主要根据遥感数 据、气象数据和 DEM 数据论述植被与其主要影 响因素的相互关系，进而得出一定的规律性。

\subsection{1 植被覆盖变化与水热因子的关系}

本文中水热因子指标包括气候因子 (气温、降 水量）和地表水热条件因子（LST、LSWI）。 通过对研究区 49 个气象站点的4-10月份气温 和降水量数据进行统计, 得出了2000-2014年
究区植被 NDVI 变化的空间特征。由图2可见, 2000-2014年间内蒙古地区植被覆盖发生了较 大变化, 研究区植被覆盖变化存在明显的区域 差异。呈显著及极显著增加趋势的区域主要集 中在阿拉善盟中部、鄂尔多斯市北部以及巴彦 淖尔市南部、通辽南部和兴安盟东部等地区, 而呈减少趋势的区域分布在呼伦贝尔市大部 分地区、赤峰市西北部、锡林郭勒盟西南部、 阿拉善盟东部及西部的一些地区。从整体上来 看, 植被覆盖呈增加趋势的区域占据绝大部分 地区, 这和前人相关研究结论基本一致 ${ }^{[10]}$ 。这 或许说明生态恢复工程对内蒙古植被恢复起 到了一定的作用。

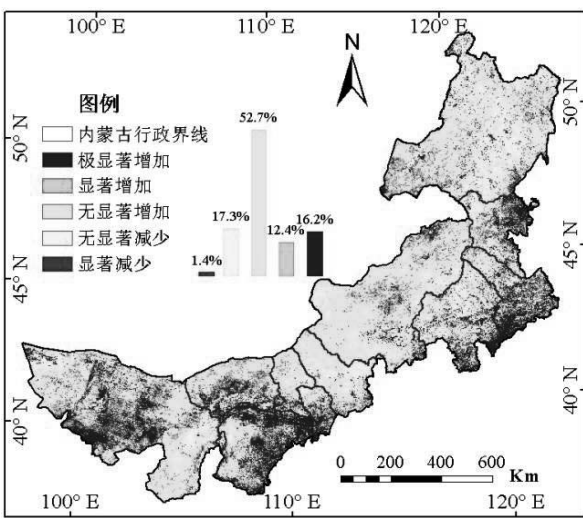

图 2 内蒙古生长季 NDVI 空间变化

气温、降水量与 NDVI 的相互关系图 (图3和4) [11]。同时对研究区4-10月份 LST 和 LSWI 数据 进行区域平均计算, 获得同时期地表水热组合 数据与 NDVI 的关系图 (图5和6)。从图4和图 6 上可以看出, 近15年来, 该地区植被 NDVI 与 降水量的相关系数为 0.931 (显著性水平: $\mathrm{p}<0.01$ ), 与 LSWI 的相关系数为 0.969 (显著 性水平: $p<0.01)$, 两种参数均与 NDVI 呈极显 著相关关系。而植被 NDVI 与气温之间呈显著 负相关关系 $(R=-0.555 \quad \mathrm{p}<0.05)$ 。与 $\mathrm{LST}$ 之 间呈无显著正相关（ $R=0.14 \quad \mathrm{p}>0.05 ）$ 。综上 所述, 降水量和地表水分含量是改变内蒙古植 被覆盖变化的主要驱动因子。地表温度的适当 上升对植被生长具有驱动作用, 而较高的气温 导致水分的蒸发散发, 使研究区干旱加剧和植 被覆盖覆盖减少。 
Risk Analysis and Crisis Response in Big Data Era (RAC-16)

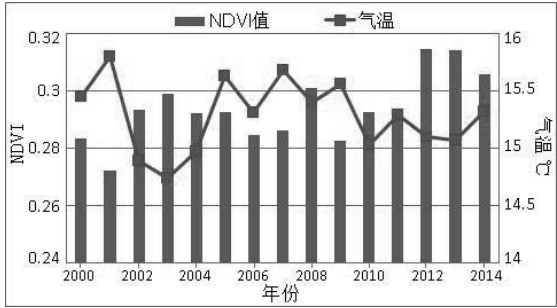

图 3 NDVI 与气温变化趋势

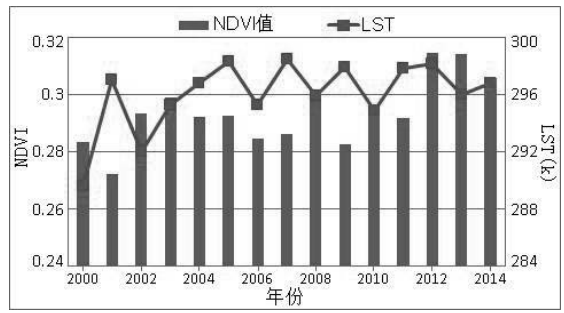

图 5 NDVI 与 LST 变化趋势

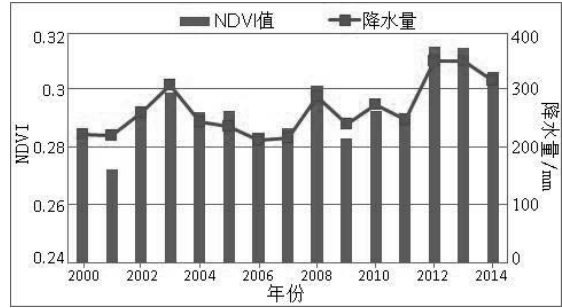

图 4 NDVI 与降水量变化趋势

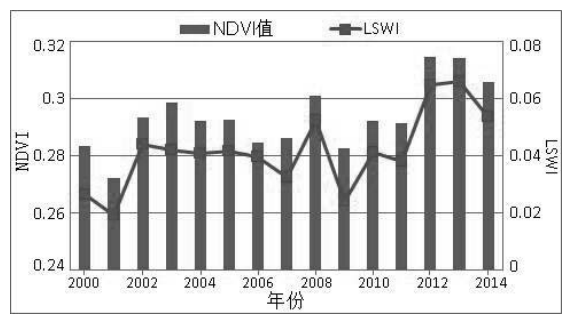

图 6 NDVI 与 LSWI 变化趋势

逐步增加; 坡度在 $15-25^{\circ}$ 之间时, 斜率保持 在0.0013左右, 基本不变; 当坡度超过 $25^{\circ}{ }^{\circ}$ 时, 斜率随坡度的增加而呈上升趋势明显。坡度平 缓的地区植被 NDVI 减少明显, 而坡度较大的 地区植被 NDVI 增加明显。

基于 DEM 数据, 以 $22.5^{\circ}$ 为区间提取不同 坡向上植被变化趋势的斜率变化情况。山坡的 朝向决定了坡面接受太阳辐射强度、辐射时间、 地面温度以及蒸发量等水热条件, 很大程度上 影响植被类型与分布特征, 同时植被也表现出 对外来干扰的承受能力的差异 ${ }^{[13]}$ 。由统计结果 显示, 总体上, 阳坡上植被变化比阴坡活跃。 坡向在 $157.5^{-247.5}{ }^{\circ}$ 和0-67. $5^{\circ}$ 之间, 植被 变化趋势相对活跃, 一天当中 $157.5-247.5^{\circ}$ 。 之间的阳坡上太阳光照时间最长, 由于太阳辐 射条件的差异引起坡向的植被变化差异, 而阴 坡0-67. $5^{\circ}$ 之间的坡向上光照时间短, 有利于 保持水分条件。由此说明太阳辐射条件和水分 条件的差异并导致变化差异性的主要原因。 上趋势斜率的变化情况。从不同坡度上研究区 植被变化趋势来看, 如图8所示, 坡度小于 15 ${ }^{\circ}$ 时, 随着坡度的增大植被 NDVI 减少趋势在 
Risk Analysis and Crisis Response in Big Data Era (RAC-16)
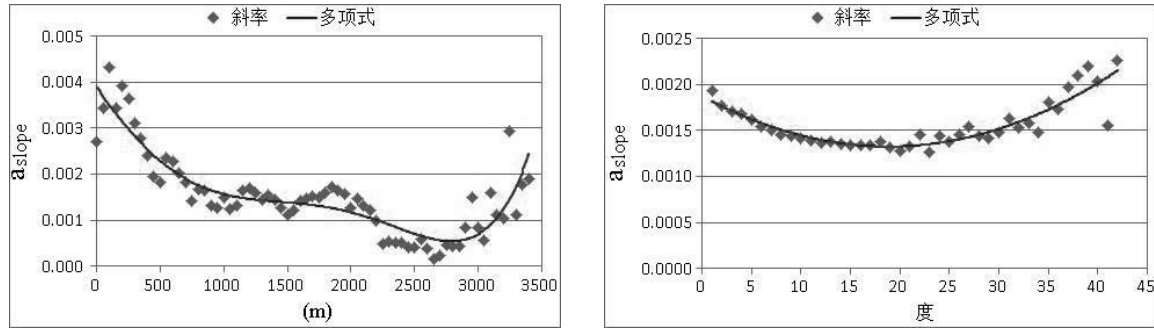

图 7 不同海拔范围内 NDVI 变化斜率的变化情况 图 8 不同坡度上 NDVI 变化的斜率的变化趋势

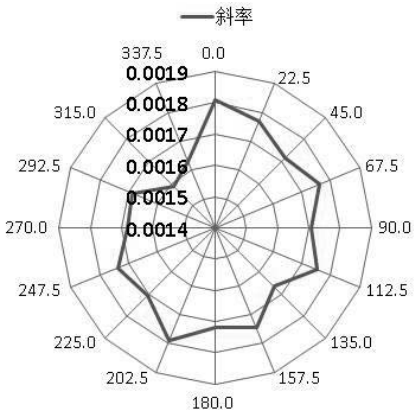

图 9 不同坡向上 NDVI 变化斜率的变化情况

\section{4. 结论与讨论}

本文利用 MODIS 数据、气象数据、DEM 数据分 析了内蒙古地区近15年来植被 NDVI 时空变化 特征及其驱动力分析, 得出了如下主要结论: 2000-2014年期间，内蒙古植被 NDVI 变化呈上 升趋势, 且波幅较大, 并且存在显著的地域差 异。近15年来呈增加趋势的区域占主导地位, 占据比例为 $81.3 \%$, 其中呈显著或极显著增加 趋势的区域主要分布在内蒙古西部以及东南 部地区, 东北部以及中部地区主要呈减少趋势 的较多。内蒙古地区植被覆盖与降水量和地表 水含量有很好的正相关关系, 对于干早地区而 言, 水分是植被覆盖变化的主要驱动因子。适 当的地表温度对植被生长具有驱动作用。而气 温一定程度上限制植被的生长, 对植被覆盖变 化起到了负作用。海拔在500-2500m 范围内植 被变化随着高程的上升而变化缓慢, 海拔大于 $2500 \mathrm{~m}$ 的区域，随着海拔的上升而植被显著恢 复。不同坡度上的植被恢复存在较大差异, 且 随着坡向有阴坡转阳坡, 植被恢复呈增加趋势。

本文主要研究了水热条件和地形因子对 生长季植被恢复的影响, 仅从区域尺度上探讨
了水热条件对内蒙古地区植被变化的影响。除 了自然驱动因子之外人类活动也是影响研究 区植被覆盖变化的主要因子之一。因此考虑到 自然和人为因素对植被覆盖变化的综合影响, 在今后的研究当中, 还需要更小时间尺度上探 讨植被变化和与自然因子响应模式。且将人类 活动和自然变化对植被覆盖变化产生的影响 进行区分, 定量评价人为因素和自然因素对植 被生长的贡献。

\section{Acknowledgements}

This study was supported by National "12th Five-Year" science and technology support project (2013BAK05B01), Inner Mongolia science and technology project (No.: 20130430).

\section{致谢}

本研究得到了资助项目：国家 “十二五” 科技支 撑计划项目（2013BAK05B01），内蒙古科技计划 项目（编号：20130430）。 


\section{参考文献}

[1] Z. Xin, J. Xu and W. Zheng. Spatiotemporal variations of vegetation cover on the Chinese Loess Plateau (1981-2006): impacts of climate changes and human activities. Science in China Series D: Earth Sciences, 2008, 51 (1):67-78.

[2] 孙艳玲, 郭鹏, 延晓冬等. 内蒙古植被覆 盖变化及其与气候、人类活动的关系. 自 然资源学报, 2010, 25(3): 407-414.

[3] 时忠杰, 高吉喜, 徐丽宏等. 内蒙古地区 近25 年植被对气温和降水变化的影响. 生态环境学报, 2011, 20(11): 1594-1601.

[4] 宋乃平, 杜灵通, 王否. 盐池县2000-2012 年植被变化及其驱动力. 生态学报, 2015, 35(22): 7377-7386.

[5] D.F. Liu, D. Wang, Y. K. Wang, L.H. Wang, X.Q. Zou. WD-RBF model and its application of hydrologic time series prediction. Journal of Risk Analysis and Crisis Response, 2013, 93(4):185-191.

[6] D.H. Mao ,Z.M. Wang , L. Li ,et al. Spatiotemporal dynamics of grassland aboveground net primary productivity and its association with climatic pattern and changes in Northern China. Ecological Indicators, 2014,41:40-48.

[7] 宋怡,马明国.基于GIMMS/AVHRR NDVI 数据的中国寒旱区植被动态及其与气候 因子的关系. 遥感学 报,2008,12(3):499-505

[8] 周锡饮,师华定,王秀茹等.蒙古高原近 30 年来土地利用变化时空特征与动因分析. 浙江农业学报,2012,24(6):1102-1110.

[9] 孙红雨,李兵.中国地表植被覆盖变化及其 与气候因子关系。遥感学报,1998, 2(3): 204-210.

[10] 周爱霞,马泽忠,周万村.大宁河流域坡度 与坡向对土地利用/覆盖变化的影响.水土 保持学报,2004,18(2):126-129.

[11] 杨元合,朴世龙.青藏高原草地植被覆盖变 化及其与气候因子的关系.植物生态学报, 2006, 30(1): 1-8.
[12] 冯朝阳,于勇, 高吉喜等. 地形因子对京西 门头沟区土地利用/覆盖变化的影响. 山 地学报, 2007, 25(3): 274-279.

[13] 戴声佩,张勃, 王海军等.中国西北地区植 被覆盖变化驱动因子分析. 干旱区地 理,2010,33(4):636-643. 